\title{
Correlation between the Childhood-Asthma Control Test and the Criterion for Clinical Asthma Control*
}

\author{
Carlos José Ortiz-Lizcano, Jürg Niederbacher-Velásquez, Luis Alfonso Díaz-Martínez\# \\ Paidós Research Group, Pediatrics Department, School of Medicine, Universidad Industrial de Santander, \\ Bucaramanga, Colombia \\ Email: "ladimar@uis.edu.co
}

Received 1 February 2016; accepted 7 May 2016; published 10 May 2016

Copyright (C) 2016 by authors and Scientific Research Publishing Inc.

This work is licensed under the Creative Commons Attribution International License (CC BY).

http://creativecommons.org/licenses/by/4.0/

c) (i) Open Access

\begin{abstract}
Setting: Three pediatric pneumatologist offices in Bucaramanga, Colombia. Objective: To establish the concordance between medical criteria and the Childhood-Asthma Control Test (cACT). Design: Study of the assessment of diagnostic technology using transverse sampling. 127 asthma patients aged between 4 and 11 years and their parents filled before clinical evaluation made by a pediatric pneumologist. Patients were classified as controlled or not controlled. Criteria validity was established comparing this classification using Cohen's kappa and performance indicators according to ROC analysis. Results: $\mathbf{7 8 \%}$ of the patients were controlled; patients who are not controlled have a higher score in cACT (mean difference: 3.25 points). Concordance among cACT subscales is acceptable $(\rho=0.554)$. cACT's sensitivity was $53.6 \%$, specificity $78.8 \%$, positive likelihood ratio (LR+) 2.53 , and negative likelihood ratio (LR-) 0.59 . The best cut-off point is 15 , with $\mathbf{9 8 \%}$ sensitivity, a specificity of $14.3 \%$, LR+ in 1.14 , and LR- in 0.14 . Conclusions: cACT is a valid tool to determine asthma control in children without replacing medical criteria or other clinical tests. In populations with difficult access to high complexity services, it is useful to decide whether urgent referral to the specialist is necessary.
\end{abstract}

\section{Keywords}

Asthma, Treatment, Control, Evaluation, Childhood-Asthma Control Test

\footnotetext{
${ }^{*}$ This paper was presented at the II Congreso Latinoamericano de Epidemiología, Medellín-Colombia, March 2014; and at the XI Congreso Colombiano de Neumología y Asma Pediátrica, Cali-Colombia, May 2014.

"Corresponding author.
}

How to cite this paper: Ortiz-Lizcano, C.J., Niederbacher-Velásquez, J. and Díaz-Martínez, L.A. (2016) Correlation between the Childhood-Asthma Control Test and the Criterion for Clinical Asthma Control. Health, 8, 623-629. 


\section{Introduction}

Asthma is the most frequent chronic disease in pediatric population. In Colombia, a study in six cities obtained a reliable approximation on the prevalence of asthma in children. However, no work has been done to establish how much asthma is controlled. Many tools and methods have been proposed to evaluate asthma, its diagnosis, control and management [1] [2].

Childhood-Asthma Control Test (cACT) was designed to be administered in primary and secondary care levels; it is cheap and easy to use and interpret [1] [3]. It is derived from the test with the same name administered to teenagers and adults, and it includes four items on the patient's disease perception, to which extra figures were added to help answer the questions, and another three items to be answered by parents [4]-[8]. The scores for the questions determine the level of control of asthma: control (20 - 27 points), partial control (15 - 19 points) and no control (fewer than 14 points). Studies have shown that clinical criteria based on complete anamnesis and an appropriate physical examination are very reliable methods to determine asthma control levels, including other alterations that may derive from management or complications. However, it seems that cACT, without replacing any medical consultation, could be a useful tool to help assess patients [7] [9]-[11].

This study aims to compare the result of medical consultation regarding the assessment of asthma control using the results obtained from cACT, thus allowing for an objective and integral tool for consultations performed by general physicians and pediatricians on asthmatic patients [1]-[4] [12] [13].

\section{Study Population and Methods}

We performed a diagnostic technology validation study during the second half of 2013. A transverse sampling was made in patients from 4 to 11 years of age. The lower limit of age is the youngest age at which children can answer the test; the upper one is the maximum set because 12-year-old or older may answer original ACT. We had verbal informed consent from their parents and verbal assent from the patients as authorized by the Institutional Review Board from the Universidad Industrial de Santander. The only selection criteria included a clinical history for asthma of at least a 4-month evolution following GINA criteria [9].

There was no exclusion criteria. All children came for asthma control with any of three pediatric pneumologists on their private offices. In the waiting room and before the consultation, we invited the parents and patients to fill in the cACT, which classifies patients as "Not controlled" ( $<14$ score points), "Partially controlled" (15 19 score points) and "Under control" ( $\geq 20$ score points). After consultation and independently from the cACT result, each physician classified them the same way, not controlled, partially controlled and under control, following GINA criteria [12].

The sample size was defined to estimate a sensitivity of $70 \%$ or more to detect no control childhood asthma; at least 120 children were needed to this aim. Statistical analysis was done using Stata/SE 12.1 for Windows ${ }^{\circledR}$ (StataCorp, College Station, TX, 2013). Evaluation of the differences among the different characteristics of studied patients was done with $\chi^{2}$ tests or ttest according to the situation, assuming an $\alpha<0.05$ difference as significant.

To establish internal consistency for cACT we performed the Cronbach's alpha test [14], both for the seven items together and for items 1 - 4 (patient's answers subscale) and items 5 - 7 (parent's answers subscale). At the same time, content validity was evaluated through main factor analysis.

The validity of cACT's criterion was determined through the comparison of the three groups resulting from the score and medical diagnosis established during the interview with categories of the same name. The diagnostic discrimination capacity of the test was estimated using Cohen's mean kappa and its standard error [15]. Afterward, we grouped the medical criteria categories using cACT's "Not controlled" and "Partially controlled" into just one, "Without control", given the fact that the purpose of the treatment is to achieve control. Thus, we calculated sensitivity, specificity and predictive data for the test with the respective 95\% confidence intervals (CI95\%) against clinical diagnosis, which was considered the gold standard [16]. We estimated ROC characteristics and a ROC (area under the curve) of the scale and both subscales, aiming to establish the best cut-off point for them [17]. Evaluated differences were considered significant when statistical tests were $\alpha<0.05$.

\section{Results}

Initially, we had 154 patients; 25 were excluded as seen in the participants of the study. Therefore, a total of 127 
patients whose ages ranged from 4 to 11 years of age (mean: 6.87; SD: 2.14 years) were included. There were 61 (48\%) girls (mean age, 6.85; SD: 2.16) and 66 (52\%) boys (mean age: 6.87; SD: 2.13) (p=0.945). From them, 14 patients (11\%) had been diagnoses with asthma within a year, 36 (28.4\%) lived with animals, and 15 (11.8\%) lived with smokers.

Clinical classification for asthma corresponded to 3 (2.4\%) patients with mild intermittent asthma, 75 (59.1\%) mild persistent, 47 (37\%) moderate persistent, and 2 (1.6\%) severe persistent. No differences were found regarding time of diagnosis, living with animals or smokers according to the asthma classification, but some were found regarding age, gender and living in urban areas (Table 1).

Control evaluation according to medical criteria corresponded to one (0.8\%) not controlled, 27 (21.2\%) partially controlled, and 99 (78\%) controlled patients. There were differences in the medical classification of control regarding clinical classification, but not in the other analyzed aspects in Table 2.

cACT categorized six (4.7\%) patients as not controlled, 30 (23.5\%) as partially controlled and 91 (71.7\%) as controlled. Dividing this classification in two groups, cACT catalogs 36 (28.3\%) patients as not controlled and $91(71.7 \%)$ as controlled.

Cronbach's alpha for the complete scale was 0.780 , while for the patient subscale it was 0.478 , and for the parent subscale it was 0.808 . With the main factor analysis we only found one dominion that includes all items and explains $94.18 \%$ of variance.

Patients without control according to medical criteria got a mean score of 19.04 (SD: 4.46) points, while for controlled patients it was 22.18 (SD: 3.82), with a mean difference of 3.15 (CI95\% 4.83 to 1.47) points (p < 0.001). The difference in the patient subscale scores between controlled and not controlled patients according to

Table 1. Clinical classification of asthma compared with demographic characteristics of patients.

\begin{tabular}{|c|c|c|c|c|c|}
\hline \multirow[b]{2}{*}{ Evaluated aspect } & \multicolumn{4}{|c|}{ Clinical classification of asthma } & \multirow[b]{2}{*}{ p value } \\
\hline & $\begin{array}{l}\text { Mild intermittent } \\
\qquad(\mathrm{n}=3)\end{array}$ & $\begin{array}{l}\text { Mild persistent } \\
\qquad(\mathrm{n}=75)\end{array}$ & $\begin{array}{l}\text { Moderate persistent } \\
\qquad(\mathrm{n}=47)\end{array}$ & $\begin{array}{l}\text { Severe persistent } \\
\qquad(\mathrm{n}=2)\end{array}$ & \\
\hline Age (years) ${ }^{*}$ & $9.33(0.58)$ & $6.83(2.23)$ & $6.68(1.97)$ & 9.0 & 0.576 \\
\hline Female & $2(3.3 \%)$ & $44(72.1 \%)$ & $14(23.0 \%)$ & $1(1.6 \%)$ & 0.018 \\
\hline Urban housing & $2(1.6 \%)$ & $74(60.2 \%)$ & $45(36.6 \%)$ & $2(1.6 \%)$ & 0.018 \\
\hline Diagnosis $<1$ year & - & $8(57.1 \%)$ & $6(42.9 \%)$ & - & 0.586 \\
\hline Living with animals & $2(5.6 \%)$ & $18(50.0 \%)$ & $16(44.4 \%)$ & - & 0.221 \\
\hline Living with smokers & - & 7 (46.7\%) & 8 (53.3\%) & - & 0.506 \\
\hline
\end{tabular}

${ }^{*}$ Mean and standard deviation.

Table 2. Medical criteria of asthma control for each of the evaluated variables.

\begin{tabular}{cccc}
\hline Evaluated aspect & \multicolumn{2}{c}{ Asthma control according to the physician } & p value \\
\cline { 2 - 3 } & Yes $(\mathrm{n}=99)$ & No $(\mathrm{n}=28)$ & 0.154 \\
Age (years) & $7.01(2.15)$ & $6.36(2.06)$ & 0.563 \\
Female & $12(19.7 \%)$ & $49(80.3 \%)$ & 0.968 \\
Urban housing & $96(78.1 \%)$ & $27(22.0 \%)$ & 0.108 \\
Diagnosis $<1$ year & $8(57.1 \%)$ & $6(42.9 \%)$ & 0.068 \\
Living with animals & $24(66.7 \%)$ & $12(33.3 \%)$ & 0.813 \\
Living with smokers & $11(73.3 \%)$ & $4(26.7 \%)$ & - \\
Clinical classification & & & \\
Mild intermittent & $3(100.0 \%)$ & $9(12.0 \%)$ & $18(38.3 \%)$ \\
Mild persistent & $66(88.0 \%)$ & $1(50.0 \%)$ \\
Moderate persistent & $29(61.7 \%)$ & 0.030 \\
Severe persistent & $1(50.0 \%)$ & & \\
\hline
\end{tabular}

\footnotetext{
${ }^{*}$ Mean and standard deviation.
} 
medical criteria is equally significant (8.25 [SD: 1.69] points vs. 9.57 [SD: 1.48], 1.32 points mean difference (CI95\% 1.96 to 0.37 ); $\mathrm{p}<0.001$ ), as is in the parent subscale (10.79 points [3.19] vs. 12.62 [2.79], 1.83 points mean difference (CI95\% 3.05 to 0.61 ); $\mathrm{p}=0.04$ ).

Table 3 shows the correlation between medical criteria and cACT for control divided in two categories. For cACT full scale under ROC area was 0.719 (CI95\% 0.602 to 0.835 ), while for the patient subscale it was 0.722 (CI95\% 0.615 to 0.829 ) and for the parent subscale it was 0.685 (CI95\% 0.564 to 0.806 ); these differences were not statistically significant $(\mathrm{p}=0.268)$.

The best cut-off point for global cACT was $\geq 15$ points, while for the patient subscale it was 7 points and for the parent subscale it was 6 points. Table 4 shows the indicators of diagnostic performance for these cut-off points.

\section{Discussion}

The results of this study show that cACT is a potentially useful tool for screening asthma control in children with this disease. This means it is possible to use it in groups of boys and girls who do not have easy access to high complexity health care services, including the decision of referral to the specialist.

The population in which we evaluated the performance of the test was similar to that reported in medical literature regarding prevalence of the different clinical types of asthma or control, and aggravating exposure factors as passive smoking or living with pets [4]-[7] [12] [18] [19]. This implies that findings could be extrapolated to other populations. Additionally, the studied population behaved similarly to what was stated in the literature: the more severe the asthma, the lower its control [5] [11]. GINA describes at least $10 \%$ of the asthmatic population as controlled, stating a high level of underestimation of the symptoms in patients with mild asthma and its under-registration [4].

Having used control medical diagnosis during the interview with the pediatric pneumologist (who was not privy to cACT's results) as a referent makes these results valid. Results for the evaluation of asthma control and

Table 3. Correlation between asthma control according to medical criteria and original CACT cut-off point.

\begin{tabular}{|c|c|c|c|}
\hline \multirow{2}{*}{ Control according to medical criteria } & \multicolumn{2}{|c|}{ Control according to C-ACT } & \multirow{2}{*}{ Total } \\
\hline & No & Yes & \\
\hline No & $15(11.8 \%)$ & $13(10.2 \%)$ & $28(22.0 \%)$ \\
\hline Yes & $21(16.5 \%)$ & $78(61.4 \%)$ & $99(78.0 \%)$ \\
\hline Total & $36(28.4 \%)$ & $91(71.6 \%)$ & $127(100 \%)$ \\
\hline Cohen’s Kappa mean & \multicolumn{3}{|c|}{$0.294(\mathrm{SE} 0.088)$} \\
\hline Sensitivity & \multicolumn{3}{|c|}{$53.6 \%$ (CI95\% 33.3 to 73.8$)$} \\
\hline Specificity & \multicolumn{3}{|c|}{$78.8 \%$ (CI95\% 70.2 to 87.4$)$} \\
\hline Positive predictive value & \multicolumn{3}{|c|}{41.7 (CI95\% 21.2 to 59.2) } \\
\hline Negative predictive value & \multicolumn{3}{|c|}{$85.7 \%$ (CI95\% 78.0 to 98.5$)$} \\
\hline Positive likelihood ratio & \multicolumn{3}{|c|}{2.53 (CI95\% 1.51 to 4.22$)$} \\
\hline Negative likelihood ratio & \multicolumn{3}{|c|}{0.59 (CI95\% 0.39 to 0.89$)$} \\
\hline
\end{tabular}

Table 4. Diagnostic performance indicators of the best cut-off points for C-ACT and its subscales.

\begin{tabular}{cccc}
\hline Diagnostic indicator & C-ACT & Patient subscale & Parent subscale \\
\hline Cut-off point & $\geq 15$ & $\geq 7$ & $\geq 6$ \\
Sensitivity (\%) & 98.0 & 96.0 & 98.0 \\
Specificity (\%) & 14.3 & 17.9 & 10.7 \\
Concordance (\%) & 79.5 & 78.7 & 78.7 \\
Positive likelihood ratio & 1.14 & 1.17 & 1.10 \\
Negative likelihood ratio & 0.14 & 0.23 & 0.19 \\
\hline
\end{tabular}


the correlation between cACT and clinical criteria were favorable. We expected 60\% concordance and we obtained 70\%. Up to now, cACT had not been compared to clinical criteria alone, the studies that showed the validity of the test were done by comparing the results from paper testing with pulmonary function and bronchial inflammation parameters like $\mathrm{VEF}_{1}$ and fractional exhaled nitrous oxide-FeNO [19]. In this study, published in 2009, Piatrecini, et al., found and adequate correlation in the results of asthma control according to cACT and FeNO in patients with recent diagnoses, while among patients in CACT follow-up there was significant correlation with $\mathrm{VEF}_{1}$ but not with FeNO. Also, Muiño, et al. [5], compared cACT with asthma control criteria according to GINA, including both clinical parameters and $\mathrm{VEF}_{1}$ values and found an adequate correlation among patients in severe conditions.

Other cACT validity elements were Cronbach's alpha values, both for the complete test and its subscales, and the existence of a unique dominion with all items that explains more than $90 \%$ variance. During the initial development of cACT, Nathan, et al., proposed 22 question items derived from an expert consensus based on existing guidelines in 2004. All items achieved significant correlation with asthma control, from which five were used for developing cACT [6].

Liu, et al., found that 12 was the best cut-off point to determine not controlled asthma established with pulmonary function tests and GINA criteria [10] [11]. In this study, we found that 15 is a better cut-off point for patients seen in Colombia, particularly in a population like the one in Bucaramanga, which has the highest asthma prevalence in the country [2]. This cut-off point implies a high sensitivity (98\%) with low specificity (14.3\%), which combined with a mediocre positive likelihood ratio (1.14) and a very acceptable negative likelihood ratio (0.14) show that this test could be used confidently to screen asthma control taking into account that for every 7 tests showing real high asthma control scores, there is one test with high scores in a patient who, in reality, is not totally controlled. These assertions require further confirmation in other populations to be able to define the best cut-off point for each clinical and population context.

We explored item behavior separately, those answered by patients and those answered by parents or caretakers. Both subscales behaved similarly, without being higher than the sum of both. However, at a certain point the patient subscale could correlate better than that of the parents or caretakers. The aim of this study was not to evaluate the behavior of both subscales. Thus, it cannot elucidate this finding, but could be used to surmise that, in case there is no reliable adult informant, the subscale that evaluates what the patient considers is happening could be used instead. It is likely that parents or caretakers do not have enough information or contact with the child or that they underestimate the symptoms, but further adequate studies on this issue are needed to establish the veracity of this hypothesis. Recently, Rodríguez-Martínez et al. [20] published that the cACT Spanish version has adequate criterion validity, adequate construct validity, adequate sensitivity to change, good internal consistency, good test-retest reliability and excellent usability when administered to 143 asthmatic children aged between 4 and 11 years resident in Bogotá, Colombia.

A weak point in both studies is that is not as objective as the spirometry; in our research, we compared two appreciations: that of the informant and that of the physician, and Rodríguez-Martínez et al. [20] compared cACT score with Pediatric Asthma Caregivers Quality of life Questionnaire score. Nevertheless, the high level of clinical criteria of the physicians as evaluators used in our study is the current available referent, due to the fact that they are the most experienced and knowledgeable about this topic. Even though spirometry is an objective tool for evaluation and it could be used with relative ease in adequate places, in four out of every five children spirometry to evaluate asthma control is not used each time the child visits for clinical control, therefore, many times clinical evaluation is just clinical, even in the most sophisticated contexts [21] [22].

\section{Conclusion}

Thus, given the fact that the population is similar to that present in other places in Colombia and Latin America and that the methodology is valid, it is possible to state that cACT is a useful tool to determine asthma control in children. It does not replace clinical control, but it could be used at different attention levels, particularly among those who have difficulties accessing high complexity health services (pediatrics, pediatric pneumology). As such, its use could become another criterion for urgent referral to the specialist.

\section{Acknowledgements}

The authors wish to thank the patients, their parents and staff of the pediatric neurologist's offices. 
No specific funding for this project was gained.

\section{Conflict of Interest}

None declared.

\section{References}

[1] Araújo, L. (2006) Natural History of Asthma. In: Reys, M.A., Aristizabal, G. and Leal, F., Ed., Pediatric Pulmonology. Infection, Allergy, and Respiratory Disease in Children, Panamericana, Bogotá, 482-486.

[2] Dennis, R.J., Caraballo, L., Garcia, E., Rojas, M.X., Rondon, M.A., Perez, A., et al. (2012) Prevalence of Asthma and Other Allergic Conditions in Colombia 2009-2010: A Cross-Sectional Study. BMC Pulmonary Medicine, 12, 17. http://dx.doi.org/10.1186/1471-2466-12-17

[3] Zitt, M.J. (2007) Advances in Inhaled Corticosteroid Pharmacology. Allergy and Asthma Proceedings, 28, $114-124$. http://dx.doi.org/10.2500/aap.2007.28.2989

[4] (2007) Expert Panel Report 3 (EPR-3): Guidelines for the Diagnosis and Management of Asthma-Summary Report 2007. Journal of Allergy and Clinical Immunology, 120, S94-S138. http://dx.doi.org/10.1016/j.jaci.2007.09.029

[5] Muiño, A., Torello, T.P. and Brea, S. (2010) Test Control Asthma in Children: Childhood ACT. Clinical Utility and Daily Practice. Archivos de Pediatria del Uruguay, 81, 78-86.

[6] Nathan, R.A., Sorkness, C.A., Kosinski, M., Schatz, M., Li, J.T., Marcus, P., et al. (2004) Development of the Asthma Control Test: A Survey for Assessing Asthma Control. Journal of Allergy and Clinical Immunology, 113, 59-65. http://dx.doi.org/10.1016/j.jaci.2003.09.008

[7] Vega, J.M., Badia, X., Badiola, C., Lopez-Vina, A., Olaguibel, J.M., Picado, C., et al. (2007) Validation of the Spanish Version of the Asthma Control Test (ACT). Journal of Asthma, 44, 867-872. http://dx.doi.org/10.1080/02770900701752615

[8] Boulet, L.P., Boulet, V. and Milot, J. (2002) How Should We Quantify Asthma Control? A Proposal. Chest, 122, 22172223. http://dx.doi.org/10.1378/chest.122.6.2217

[9] Rodrigo, G.J., Arcos, J.P., Nannini, L.J., Neffen, H., Broin, M.G., Contrera, M., et al. (2008) Reliability and Factor Analysis of the Spanish Version of the Asthma Control Test. Annals of Allergy, Asthma \& Immunology, 100, 17-22. http://dx.doi.org/10.1016/S1081-1206(10)60399-7

[10] Liu, A.H., Zeiger, R., Sorkness, C., Mahr, T., Ostrom, N., Burgess, S., et al. (2007) Development and Cross-Sectional Validation of the Childhood Asthma Control Test. Journal of Allergy and Clinical Immunology, 119, 817-825. http://dx.doi.org/10.1016/j.jaci.2006.12.662

[11] Liu, A.H., Zeiger, R.S., Sorkness, C.A., Ostrom, N.K., Chipps, B.E., Rosa, K., et al. (2010) The Childhood Asthma Control Test: Retrospective Determination and Clinical Validation of a Cut Point to Identify Children with Very Poorly Controlled Asthma. Journal of Allergy and Clinical Immunology, 126, 267-273, 273.e1.

[12] Global Strategy for Asthma Management and Prevention, Revised 2006. www.ginaasthma.org/Guidelineitem

[13] Wenzel, S.E. (2006) Asthma: Defining of the Persistent Adult Phenotypes. The Lancet, 368, 804-813. http://dx.doi.org/10.1016/S0140-6736(06)69290-8

[14] Cronbach, L.J. (1951) Coefficient Alpha and the Internal Structure of Tests. Psychometrika, 16, 297-334. http://dx.doi.org/10.1007/BF02310555

[15] Cohen, J. (1960) A Coefficient of Agreement for Nominal Scales. Educational and Psychological Measurement, 20, 37-46. http://dx.doi.org/10.1177/001316446002000104

[16] Diamond, G.A. (1986) Reverend Bayes’ Silent Majority. An Alternative Factor Affecting Sensitivity and Specificity of Exercise Electrocardiography. American Journal of Cardiology, 57, 1175-1180. http://dx.doi.org/10.1016/0002-9149(86)90694-6

[17] Pepe, M.S. (2003) The Statistical Evaluation of Medical Tests for Classification and Prediction. Oxford University Press, New York.

[18] Brandão, H.V., Cruz, C.S., Guimarães, A., Camargos, P.A. and Cruz, Á.A. (2010) Predictors of Hospital Admission Due to Asthma in Children and Adolescents Enrolled in an Asthma Control Program. Jornal Brasileiro de Pneumologia, 36, 700-706.

[19] Piacentini, G.L., et.al. (2009) Childhood Asthma Control Test and Airway Inflammation Evaluation in Asthmatic Children. Allergy, 64, 1753-1757. http://dx.doi.org/10.1111/j.1398-9995.2009.02068.x

[20] Rodríguez-Martínez, C.E., Melo-Rojas, A., Restrepo-Gualteros, S.M., Sossa-Briceño, M.P. and Niño, G. (2014) Vali- 
dation of the Spanish Version of the Childhood Asthma Control Test (cACT) in a Population of Hispanic Children. Journal of Asthma, 51, 855-862. http://dx.doi.org/10.3109/02770903.2014.921197

[21] Jat, K.R. (2013) Spirometry in Children. Primary Care Respiratory Journal, 22, 221-229. http://dx.doi.org/10.4104/pcrj.2013.00042

[22] Gaffin, J.M., Shotola, N.L., Martin, T.R. and Phipatanakul, W. (2010) Clinically Useful Spirometry in Preschool-Aged Children: Evaluation of the 2007 American Thoracic Society Guidelines. Journal of Asthma, 47, 762-767. http://dx.doi.org/10.3109/02770903.2010.485664 